\title{
Maximising the value of irrigation through improved use of soil resources and sensor technology
}

\author{
John J. DREWRY ${ }^{1 *}$, Carolyn B. HEDLEY ${ }^{1}$ and Jagath EKANAYAKE ${ }^{2}$ \\ ${ }^{1}$ Manaaki Whenua - Landcare Research, Private Bag 11052, Palmerston North, New Zealand \\ ${ }^{2}$ Manaaki Whenua - Landcare Research, PO Box 69040, Lincoln, New Zealand \\ *Corresponding author: drewryj@landcareresearch.co.nz
}

\begin{abstract}
This paper presents a case-study approach focussing on variability of soils, soil physical properties, and how the use of proximal sensor surveys and soil moisture monitoring can be used to improve irrigation management at fine spatial scales $(<10 \mathrm{~m})$. Proximal sensor survey data have been used to map soil variability and statistically derive management zones, which are then correlated with S-map siblings using soil moisture release curves. At the first case study site, soil moisture monitoring of these management zones showed the poorly drained soil had wetter conditions than the other zones, which is likely to have been a factor contributing to reduced barley yield. Less irrigation could therefore have been applied to the poorly drained soil, with a saving in cost and yield penalty. In the second case study, we provide an overview of research focussing on practical applications of near real-time soil moisture monitoring and visualisation through smart phone apps, enabling new irrigation software and hardware to be matched to specific farm circumstances, so soils and crops can be managed to reduce water and nutrient losses.
\end{abstract}

Keywords: Soil water release, available water capacity, LoRa, variable rate irrigation.

\section{Introduction}

Soil physical properties affect air and water transmission through soil, water storage and its availability to plants, and pasture and crop yields (Drewry et al. 2008; Houlbrooke \& Laurenson 2013). Soil physical properties, such as readily available water-holding capacity, are key influences on irrigation management. Soil hydrological properties are fundamental drivers affecting environmental outcomes, such as soil drainage and nutrient loss. Some soils have reduced capacity for water storage, such as soils of high stone content, which are common in several agricultural areas of New Zealand (Hedley \& Yule 2011; Carrick et al. 2013). If present on-farm, these soils add to the variability of soil and increase management complexity. Stony soils are also vulnerable to nutrient losses (Hedley \& Yule 2011; Carrick et al. 2013).

Improved irrigation management enabled by precision agriculture technologies, coupled with good farm practices can help reduce farm inputs, improve efficient use of water as well as farm profit, and help minimise nutrient losses (Hedley et al. 2009; Hedley 2015). These technologies include proximal soil sensing that enables integration of the soil spatial variability into development of zones that require different management, i.e. management zones. Variable rate irrigation (VRI) systems enable the variable application of irrigation water or other inputs, e.g. fertiliser, reducing drainage and nutrient losses compared with uniformly applied irrigation water (McDowell 2017; Drewry et al. 2019). There is a need to provide farmers with new tools that enable further improvements to productivity, efficiency of water use on-farm, and reduced environmental impacts. Near real-time soil moisture measurements using wireless sensor networks, (WSNs; Ekanayake \& Hedley 2018) in management zones are essential to provide farmers with high-resolution spatial and temporal soil moisture status to schedule irrigation wisely. Previous technologies involved bulky data loggers, often with limited power supplies available and requiring cabling to sensors, that made spatial monitoring of soil moisture difficult and costly.

The aim of this paper is to present a case-study approach focussing on variable soils, soil physical properties, and how proximal sensing can improve subpaddock management. We report how these techniques, coupled with development of new modelling methods and new technologies for soil moisture monitoring, can improve irrigation management on variable soils to improve crop yields and water use efficiency. We also emphasise practical applications for farmers.

\section{Case study 1: High-resolution mapping}

This case study demonstrates how the use of proximal sensing and improved soil information, and management zones, can lead to improved information for farmer decision-making.

\section{Materials and Methods \\ Site description}

The 269-ha farm is an arable operation in central Hawke's Bay, with approximately 60\% (147 ha) 
of the farm cropped, including barley, grass seed, sweetcorn, peas, beans, wheat, maize, and lucerne, and the remainder of the farm in livestock grazing. Annual rainfall is $960 \mathrm{~mm} /$ year. Approximately 94 ha of the cropped portion is irrigated with linear and centre pivot systems. A $240-\mathrm{m}$ towable pivot irrigates 33 ha. The farming operation currently uses weekly neutron probe measurements for irrigation scheduling. Neutron probes have a relatively large exploration radius (15$70 \mathrm{~cm}$ ) depending on moisture content, compared with other sensors. The same amount of water is applied irrespective of location based on lowest moisture content to avoid plant stress and yield reduction. Total irrigation applied to a barley crop was $150 \mathrm{~mm}$ between November 2015 and early January 2016.

\section{Soil-sensor survey and data processing}

An electromagnetic (EM) sensor survey was conducted on a 33-ha paddock using a Dualem 1s sensor (https:// www.agrioptics.co.nz/) at a 12-m swath width on 18 April 2014. The sensor simultaneously measures apparent electrical conductivity (EC) to a soil depth of approximately $0.6 \mathrm{~m}$ (shallow) and $1.3 \mathrm{~m}$ (deep). Soil $\mathrm{EC}$ relates to texture and moisture differences in nonsaline conditions; and the conducting pathways in finer, wetter soils are greater than in coarser, drier soils so that they return higher EC values. The survey system combines an electromagnetic sensor with accurate GPS logging to provide a georeferenced high-resolution $(\leq 12 \mathrm{~m})$ EC dataset. Geostatistical analysis of the raw data was undertaken in R (R Core Team 2018) using a three-step process. First, a geostatistical analysis was undertaken to investigate the spatial autocorrelation of the point data by variogram analysis, the variogram was then kriged to produce a map, and finally cluster analysis was used to classify the area into relatively homogeneous EC regions, using QGIS software (QGIS Development Team, 2018). Three classes (low, intermediate and high EC) were identified and these were geographically split into three management zones (1-3), which were ground-truthed by traditional soil survey at 1:12,100 scale with one soil observation every 1.5 ha.

\section{Soil physical properties}

Soil physical properties were sampled in the three management zones identified above in January 2015. Soil pits were excavated at three replicate positions in each of the three zones. Intact soil core samples were carefully carved out vertically from steps dug into the soil pits at $10-18 \mathrm{~cm}$ and $40-48 \mathrm{~cm}$ soil depths. The soil cores were used for laboratory determination of the soil water release (SWR) curve measuring water content at $-2.5,-5,-10,-20,-40,-100,-300 \mathrm{kPa}$. Rings filled with $2-\mathrm{mm}$ sieved soil were used to measure the soil moisture content at $-1500 \mathrm{kPa}$ matric potential, as an estimate of the permanent wilting point. Available water capacity (AWC) was then determined as the difference between soil moisture content at a matric potential of $-10 \mathrm{kPa}$ and $-1500 \mathrm{KPa}$. Macroporosity was determined at $-5 \mathrm{kPa}$, and unsaturated hydraulic conductivity (Kunsat) at $-0.4 \mathrm{kPa}$. For Kunsat, the geometric mean is reported. Methods are described elsewhere (Gradwell \& Birrell 1979; Cook et al. 1993) and at https://www.landcareresearch.co.nz/resources/ laboratories/soil-physics-laboratory.

\section{Modelling approach to link field soil physical properties to S-map soil siblings}

The SWR curves derived from the soil cores were compared with those of S-map soil mapping units ('siblings') that occur in the region of interest using a method developed by Pollacco et al. (2016a, 2016b). S-map is the national soil information system (Lilburne et al. 2012; McNeill et al. 2018) consisting of a national soil map linked to a database of soil attributes including soil physical and hydraulic properties. Briefly, the method automatically selects S-map sibling options for the mapped area and then compares SWR curves for each sibling (from the national database) with those measured for each management zone, to find the best fit. The results of the analysis were checked against field soil observations made at the time of soil sampling.

\section{Yield and soil moisture monitoring}

Crop yield was assessed just before mechanical harvest by manual sampling in four replicated $1-\mathrm{m}^{2}$ plots in each management zone. Soil moisture was monitored using three replicate measurements obtained by a neutron probe (CPN International 503DR Hydroprobe) in each management zone on a weekly basis throughout the irrigation season. Soil moisture content measurements were taken at $10-\mathrm{cm}$ intervals to $80 \mathrm{~cm}$ depth. Rainfall and irrigation data were also recorded. A daily soil water balance approach was used with the soil moisture measurements to determine daily soil moisture deficit and when drainage and/or runoff events occurred. Mean values from 3 neutron probe tube readings were provided per zone so variation of the data per tube was not determined.

\section{Results}

\section{Soil sensor survey}

Results of the electromagnetic survey are shown in Figure 1a with poorly drained soil represented by dark grey areas. The survey results were used to classify three management zones: 1-3 (Figure 1b).

\section{Soil physical properties and linkage to S-map}

From the site survey, the predominant soil in 

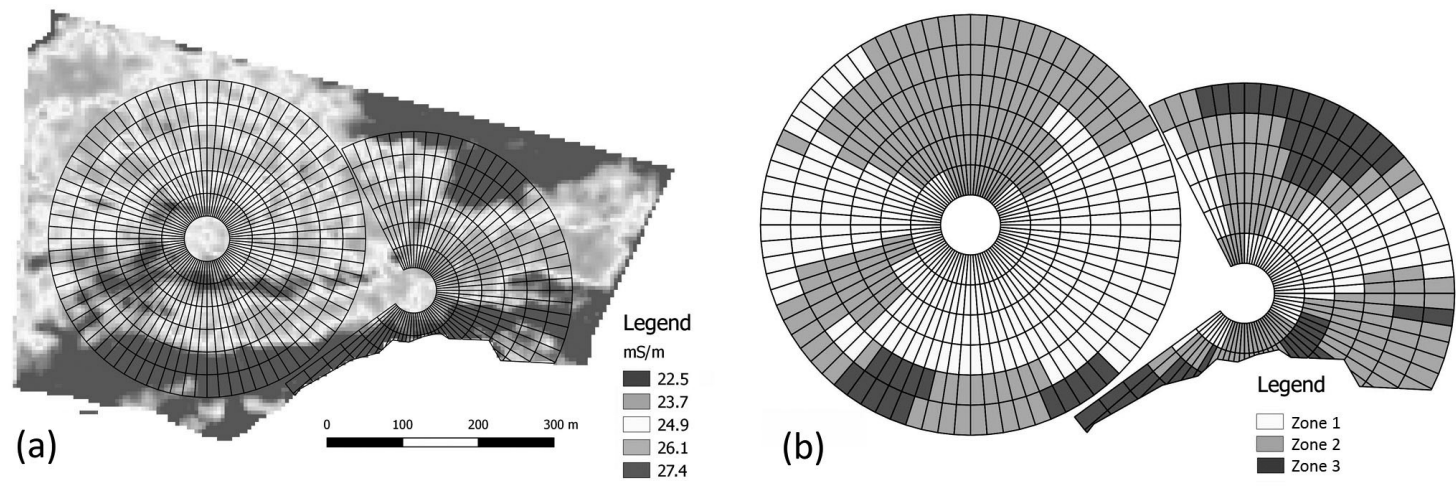

Figure 1 (a) EC sensor survey map of soil differences on 33 ha of a central Hawke's Bay farm, and (b) three management zones $(1-3)$, overlaid by pivot segments.

management zone 1 was well drained, classified as a Typic Allophanic Brown Soil, and the S-map soil sibling was matched as Tarar 6a.1 (Takapau sandy loam). The S-map soil sibling in zone 2 was matched as Tarar_6a.1 (Takapau silt loam). The soil in zone 3 was poorly drained, classified as Argillic Duric Pallic Soil, with the S-map sibling matched as Okawa_1a.1 (Poporangi sandy loam).

Soil volumetric water content (VWC) at field capacity $(-10 \mathrm{kPa})$ and permanent wilting point $(-1500$ $\mathrm{kPa}$ ) measurements obtained from the soil cores, together with the matched S-map sibling names from the modelling approach (Pollacco et al. 2016a, 2016b) are presented in Table 1, as well as profile available water (PAW) to $100 \mathrm{~cm}$. PAW is defined in S-map as the amount of water potentially available to plant growth that can be stored in the soil to a specified depth (https:// smap.landcareresearch.co.nz/help/glossary/). PAW was adjusted for profile stone content. Some stones were present in the Tarar 6a.1 siblings, ranging from 10 to $30 \%$ stones over $30-60 \mathrm{~cm}$ depth (Table 1 ), and $70 \%$ stones over $60-100 \mathrm{~cm}$ depth.

The Okawa_1a.1 sibling (Poporangi soil) had a dense duripan within the 30-60 $\mathrm{cm}$ depth, impeding roots and water movement. This duripan causes this soil in zone 3 to be poorly drained, with high bulk density, restricted macroporosity and very low Kunsat at depth (Table 2). It is this duripan and these physical properties (rather than stone content), with consequently poor drainage, that affect the number of days the soil was saturated, and therefore reduced crop yield (Table 3 ).

\section{Barley crop yield and soil drainage}

Barley crop yields were lower in the poorly drained soil in zone 3 than in the other two zones (Table 3). Soil moisture monitoring data indicated that the

Table 1 Zone, volumetric water content $(\mathrm{VWC})$ at field capacity $(-10 \mathrm{kPa})$ and permanent wilting point $(-1500 \mathrm{kPa})$, profile available water $\left(\mathrm{PAW}_{100}\right)$ for $0-100 \mathrm{~cm}$, and stone content at $30-60 \mathrm{~cm}$

\begin{tabular}{|c|c|c|c|c|c|c|}
\hline Zone & $\begin{array}{c}\text { Area } \\
\text { (ha) }\end{array}$ & $\begin{array}{c}\text { VWC (\%) } \\
\text { at }-10 \mathrm{kPa}\end{array}$ & $\begin{array}{c}\text { VWC (\%) } \\
\text { at }-1500 \mathrm{kPa}\end{array}$ & $\begin{array}{l}\text { S-map } \\
\text { sibling }\end{array}$ & $\begin{array}{c}\text { Mean PAW } \\
(\mathrm{mm})(\mathrm{std} \mathrm{dev})\end{array}$ & $\begin{array}{l}\text { Stone content } \\
\text { (\%) } 30-60 \mathrm{~cm}\end{array}$ \\
\hline 1 & 14 & 43.3 & 26.0 & Tarar_6a.1 & $94(10)$ & 30 \\
\hline 2 & 13 & 44.6 & 24.1 & Tarar_6a.1 & $99(15)$ & 10 \\
\hline 3 & 6 & 43.5 & 27.1 & Okawa_1a.1 & $58(11)$ & 0 (duripan) \\
\hline
\end{tabular}

Table 2 Zone, soil depth, bulk density, macroporosity ( $-5 \mathrm{kPa}$; pores $>60 \mathrm{~mm})$ and unsaturated hydraulic conductivity $(-0.4 \mathrm{kPa})$

\begin{tabular}{lcccc}
\hline Zone & Depth $(\mathbf{c m})$ & Bulk density $\left(\mathbf{M g} / \mathbf{m}^{3}\right)$ & Macroporosity at $\mathbf{- 5} \mathbf{~ k P a}(\% \mathrm{v} / \mathrm{v})$ & Kunsat at $-\mathbf{0 . 4} \mathbf{~ k P a}(\mathbf{m m} / \mathbf{h})$ \\
\hline 1 & $10-18$ & 0.86 & 16.2 & 68 \\
& $40-48$ & 1.09 & 17.1 & 95 \\
2 & $10-18$ & 0.81 & 20.9 & 98 \\
& $40-48$ & 1.04 & 20.8 & 102 \\
3 & $10-18$ & 1.15 & 10.8 & 16 \\
& $40-48$ & 1.72 & 6.3 & 1 \\
\hline
\end{tabular}


Table 3 Barley yield, no. days soil was saturated (12/11/15 to 21/1/16), and soil drainage/runoff for the management zone soils

\begin{tabular}{lccc}
\hline Soil, management zone & Yield (t/ha), (std dev) & No. days soil was saturated & Drainage/ runoff (mm) \\
\hline Well drained, Takapau sandy loam, 1 & $8.9(0.8)$ & 4 & 5 \\
Mod to well drained, Takapau silt loam, 2 & $10.5(0.9)$ & 6 & 26 \\
Poorly drained, Poporangi sandy loam, 3 & $2.6(2.3)$ & 16 & 69 \\
\hline
\end{tabular}

poorly drained soil in zone 3 was more often near or at saturation than the other soils (Figure 2; Table 3), whereas the other zones often had a soil moisture deficit (Figure 2).

\section{Discussion}

This case study demonstrated the benefits of mapping variable soils while considering their different water storage and physical properties for potentially applying changes in irrigation management. In this case study, the poorly drained Poporangi soil in zone 3 had a duripan subsoil, which was easily seen in the soil survey excavated pits. In addition, the EM mapping accurately delineated the duripan's area of influence through elevated EC readings. The duripan subsoil had very low macroporosity and Kunsat laboratory results. Soil moisture monitoring demonstrated that this poorly drained zone 3 soil had wetter conditions, with $69-\mathrm{mm}$ of drainage or runoff during the irrigation season. All three zones had been irrigated to the same extent but this surplus water indicates that the soil in
Zone 3 did not need as much irrigation as the other two zones. Zone- 3 soil stayed close to saturation during the irrigation season due to impeded drainage, and this is likely to have been a contributing factor to the reduced barley crop yield in that area. It is well understood that poor soil structure and aeration, with wet conditions, reduce crop yield (Drewry et al. 2008).

The farming operation currently uses weekly neutron probe measurements for irrigation scheduling with irrigation applied based on the Takapau soils to avoid plant stress and yield reduction. However, this approach led to the poorly drained Poporangi soil being overwatered and produced a lower yielding crop. The use of a VRI system could be an option to consider in the future, but the pivot is towable and is also used on other parts of the farm. Therefore, any benefits of adopting a VRI system would have to be weighed against implementation costs. An adaption for VRI would be required to implement this management change. For zone 3 , this could be a water cost saving of $\$ 600 / \mathrm{yr}$ (assuming $\$ 2 / \mathrm{mm} / \mathrm{ha} / \mathrm{yr}$ ), plus potential yield penalty

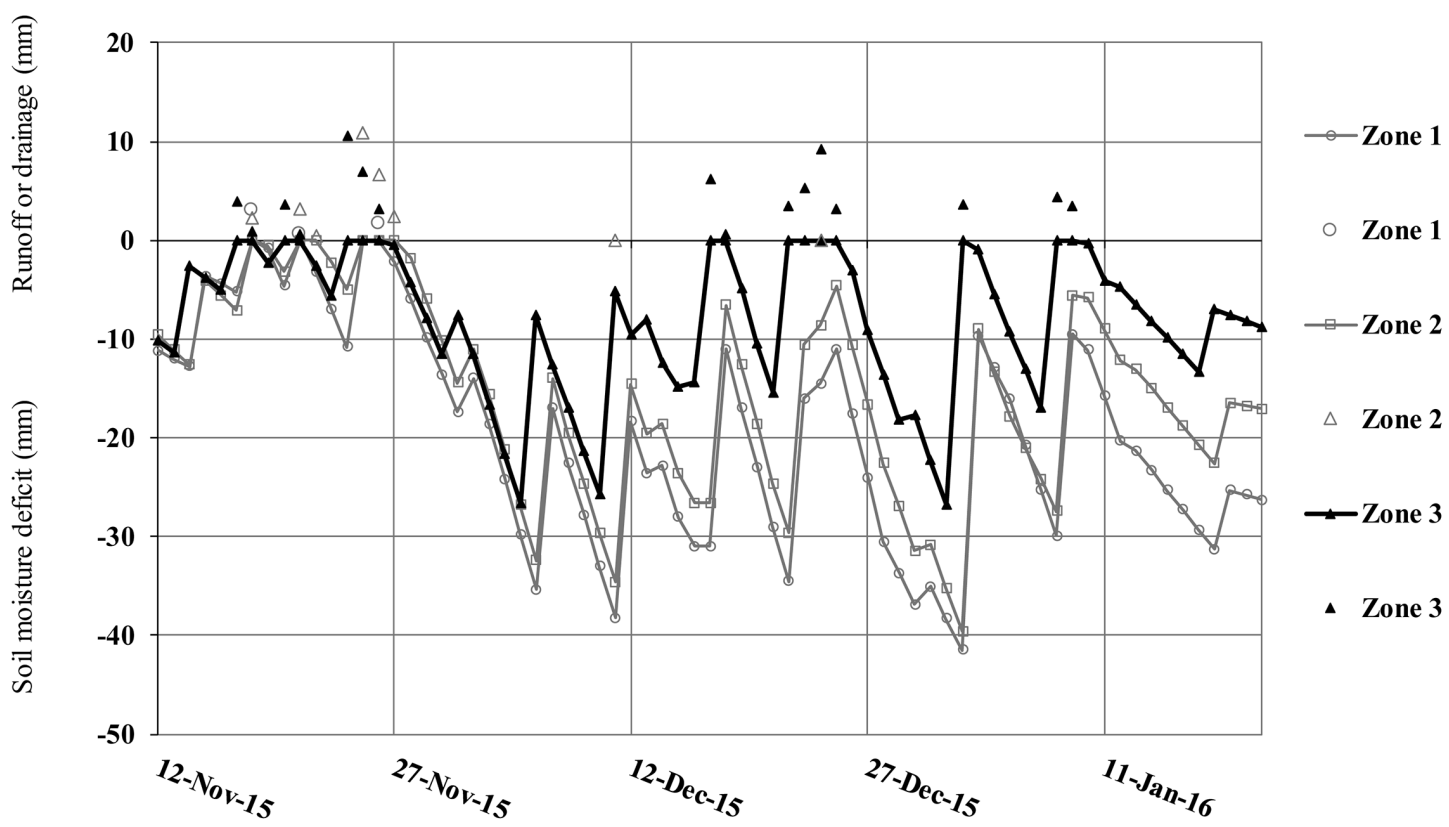

Figure 2 Soil moisture deficit $(\mathrm{mm})$ (joined data points) and runoff/drainage $(\mathrm{mm})$ (mean of 3 individual data points) for management zones 1-3 determined using neutron-probe monitoring. 
saving of approximately $\$ 2400$ (assuming yield $2 \mathrm{t} / \mathrm{ha} /$ yr). In this case, VRI could save $\$ 3000 / y r$, which could be used to estimate a pay-back period for investing in VRI. We conclude that $60 \mathrm{~mm}$ less irrigation could have been applied to the 5 ha of poorly drained soil, within the 33-ha paddock of this case study. The extent of soil variability can differ between farms, so assessment of the benefits has to be on a case-by-case basis.

The use of VRI, compared with uniform or fixed applications, can lead to improved grain yield and water use efficiency (Sharp \& Hedley 2018), and reduced nutrient losses and irrigation water applied (McDowell 2017; Drewry et al. 2019). When compared with fixed application and scheduling of irrigation water, Drewry et al. (2019) showed, for three Hawke's Bay case study farms, that VRI reduced water applied by $66 \%$ to $91 \%$, reduced modelled $\mathrm{N}$

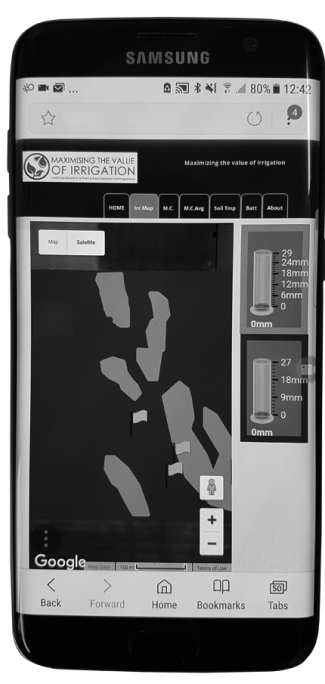
loss by $46 \%$ to $72 \%$, and reduced soil drainage by $47 \%$ to $70 \%$.

A spatial framework was developed (Sharp \& Hedley 2018) as part of the larger research programme but was not part of this case study. This framework, coupled with real-time soil moisture monitoring via WSNs (next section), has the potential to improve farm productivity and resource use.

\section{Case study 2: Soil moisture monitoring tools for irrigation management}

This case study presents a summary of near real-time soil moisture monitoring and visualisation for use by farmers in order to highlight the potential benefits of this type of technology.

\section{Materials and Methods}

Near real-time soil moisture monitoring systems were established on three farms (in Hawke's Bay, Manawatu and Canterbury), using a WSN based on Digimesh and LoRa radio technologies, with method details described elsewhere (Ekanayake \& Hedley 2018). For irrigation scheduling, graphs with control lines were generated using near real-time spatial soil moisture status and soil hydraulic property data for management zones (see Figure 3). This provided information about when to start and stop irrigation and the amount of irrigation to apply. Smart phone apps were developed for the casestudy farmers.

\section{Results}

The latest WSNs use new LoRa radio technology as this was found to be extremely robust on-farm (Ekanayake $\&$ Hedley 2018). It has a very long battery life ( $>20$ years) and LoRA connected sensors have a range of $>10 \mathrm{~km}$ in line of sight. It uses a cloud server for data storage and access. The smart phone apps developed for the farmers to view information in real-time show a cylinder volume for each soil management zone, which represents the maximum AWC and the empty portion shows the deficit (Figure 3). This visualisation proved popular among the case-study farmers and is also
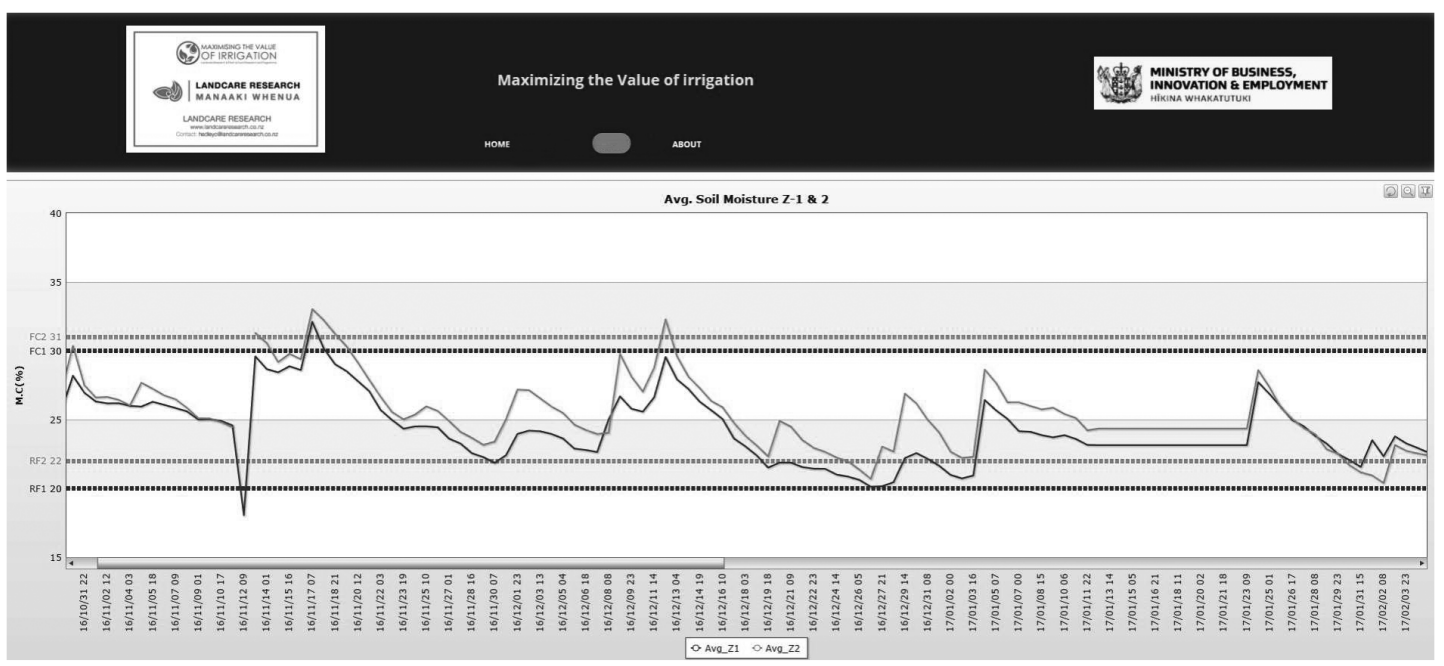

Figure 3 Screen image of the soil moisture smart phone app (above left) and irrigation scheduling tool (above), which shows soil moisture between field capacity and refill point. 
available for tablets and desktops. One farmer indicated the app helped him make more informed decisions about irrigation scheduling.

\section{Discussion}

The WSN technology was found to be beneficial for precise irrigation scheduling in other case studies (data not shown) by providing continuous monitoring data. This technology is also useful to better understand temporal change of some soil hydraulic properties using near real-time soil moisture data, which was previously not possible (Ekanayake \& Hedley 2018). However, further research is needed to develop high-resolution temporal relationships with soil physical techniques and soil functions.

\section{Conclusions}

The use of precision sensor surveys and soil moisture monitoring, coupled with S-map and an understanding of soil water storage and physical properties in Case study 1 , showed there is potential to improve targeted on-farm irrigation, and improve crop yields. Development of wireless sensor networks coupled with smart phone app technologies proved popular among farmers in Case study 2. These are practical tools for farmers for timely decision-making to increase crop yield, better manage freshwater resources for irrigation, and reduce environmental impact such as drainage, and therefore nutrient loss. These tools could be deployed more widely.

\section{ACKNOWLEDGEMENTS}

We thank the farmers for access to the farms, AgriOptics for providing EM survey data, Pierre Roudier for processing the EM data, Andrew Manderson for soil survey, the Foundation for Arable Research for yield data, and John Dando for soil physical laboratory analyses. Principal funding was provided by the New Zealand Ministry of Business, Innovation and Employment for the programme, Maximising the Value of Irrigation, (contract CO9X1309), which was jointly led by Manaaki Whenua - Landcare Research and The New Zealand Institute for Plant and Food Research. Cofunding was provided from the Foundation for Arable Research, Horticulture New Zealand, Environment Canterbury, Hawke's Bay Regional Council, and Irrigation New Zealand.

\section{REFERENCES}

Carrick S, Palmer D, Webb T, Scott J, Lilburne L. 2013. Stony soils are a major challenge for nutrient management under irrigation development. Presented at: Accurate and efficient use of nutrients on farms. Palmerston North. 8 p.
Cook F, Lilley G, Nunns R. 1993. Unsaturated hydraulic conductivity and sorptivity: labora-tory measurement. In: Carter M Ed. Soil sampling and methods of analysis. pp. 615-624. Boca Raton, FL: Lewis Publishers.

Drewry JJ, Cameron KC, Buchan GD. 2008. Pasture yield and soil physical property responses to soil compaction from treading and grazing: a review. Australian Journal of Soil Research 46: 237-256.

Drewry JJ, Manderson AK, Hedley CB. 2019. Evaluation of irrigation strategies for arable farms to mitigate nitrogen loss using the OVERSEER model. Presented at: Nutrient loss mitigations for compliance in agriculture. Fertilizer and Lime Research Centre, Massey University. Palmerston North. 11 p.

Ekanayake JC, Hedley CB. 2018. Advances in information provision from wireless sensor networks for irrigated crops. Wireless Sensor Network 10: 71-92.

Gradwell MW, Birrell KS. 1979. Methods for physical analysis of soils. [New Zealand Soil Bureau Scientific Report 10C]. Lower Hutt: New Zealand Soil Bureau Department of Scientific and Industrial Research, 62 p.

Hedley C. 2015. The role of precision agriculture for improved nutrient management on farms. Journal of the Science of Food and Agriculture 95: 12-19.

Hedley CB, Yule IJ. 2011. Soil water status maps for variable rate irrigation. In: Clay D, Shanahan J, Pierce F. Eds. GIS applications in agriculture. Volume 2. Nutrient management for energy efficiency, pp. 173190. Boca Raton, FL: CRC Press.

Hedley CB, Yule I, Tuohy MP, Vogeler I. 2009. Key performance indicators for simulated variablerate irrigation of variable soils in humid regions. Transactions of the American Society of Agricultural and Biological Engineers 52: 1575-1584.

Houlbrooke DJ, Laurenson S. 2013. Effect of sheep and cattle treading damage on soil microporosity and soil water holding capacity. Agricultural Water Management 121: 81-84.

Lilburne LR, Hewitt AE, Webb TW. 2012. Soil and informatics science combine to develop S-map: A new generation soil information system for New Zealand. Geoderma 170: 232-238.

McDowell RW. 2017. Does variable rate irrigation decrease nutrient leaching losses from grazed dairy farming? Soil Use and Management 33: 530-537.

McNeill SJ, Lilburne LR, Carrick S, Webb TH, Cuthill T. 2018. Pedotransfer functions for the soil water characteristics of New Zealand soils using S-map information. Geoderma 326: 96-110.

Pollacco JP, Hedley C, McNeill S. 2016a. Linking field measurements of soil moisture to S-map information. Landcare Research Contract Report LC2652. 9 p. 
https://www.researchgate.net/publication/315450198 Linking_field_measurements_of_soil_moisture_to_Smap_information

Pollacco J, Hedley CB, Roudier P, Ekanayake J, Lilburne L. 2016b. Modelling increased irrigation efficiency and reduced leaching with variable rate irrigation in combination with S-Map data. Presented at: Proceeding of the New Zealand and Australian Joint Soil Science Society Conference. Queenstown. QGIS Development Team. 2018. QGIS Geographic
Information System. Open Source Geospatial Foundation Project. http://qgis.osgeo.org

R Core Team. 2018. R: A language and environment for statistical computing. Vienna, Austria: R Foundation for Statistical Computing.

Sharp J, Hedley C. 2018. Application of a systems model to a spatially complex irrigated agricultural system: a case study. Presented at: Proceedings of the 14th International Conference on Precision Agriculture. Montreal, Canada. 9 p. 
